\title{
Epidemiology of menstrual disorders in developing countries: a systematic review
}

\section{Introduction}

In developing countries, priority setting in the health sector traditionally focuses on the principal causes of mortality. More recently, the Global Burden of Disease approach incorporates assessment of morbidity and quality of life in identifying priorities. Yet, although investigations in various developing countries reveal that women are concerned by menstrual disorders, little attention is paid to understanding or ameliorating women's menstrual complaints. ${ }^{1}$ Menstrual dysfunction, like other aspects of sexual and reproductive health, is not included in the Global Burden of Disease estimates $^{2,3}$ and, even as reproductive health programs expand their focus to address gynaecologic morbidity, the utility of evaluating and treating menstrual problems is not generally considered. Available data from developing countries on the frequency of menstrual disorders and their impact on women's health status, quality of life and social integration suggest that evaluation and treatment of menstrual complaints should be given a higher priority in primary care programs. This article reviews the literature on the prevalence of menstrual morbidity in developing countries and suggests a strategy for improving the quality of services provided to women with menstrual complaints.

\section{Methods}

We identified published and unpublished studies with information on the prevalence of menstrual disorders from 1970 through mid-2002 by systematically searching Medline, Popline and Lilacs and by reviewing the citation list for each published study. We also contacted researchers who have conducted community-based studies of gynaecological morbidity to ascertain whether they had information about menstrual morbidities in their databases. We were unable to obtain detailed information from two studies, but results of those studies are similar to those discussed here.

Some population-based surveys of general health or gynaecological morbidity include questions about menstrual complaints. In the late 1970s, the World Health Organization (WHO) conducted a multicountry cross sectional survey of Family Formation Patterns and Health.,
Information on the prevalence of menstrual complaints in the past three months was obtained in seven countries (Table 1). These data permit cross national comparisons in so far as similar questions with a similar time reference were asked. However, no definitions were provided and considerable variation in the interpretation of questions among individuals and across cultures is likely.

Approximately a dozen subsequent surveys, including community-based, clinic-based and one national census, include some information on menstrual morbidities ${ }^{6-29}$ (Table 2). A few health surveys of special populations, such as factory workers in Vietnam ${ }^{17}$ and medical students in Venezuela, ${ }^{27,28}$ have also included relevant questions on menstrual disorders. These surveys vary considerably in the definition of and reference period for menstrual dysfunction, limiting their comparability. However, most provide precise definitions and several include a gynaecological evaluation thus permitting evaluation of the validity and reliability of self-reported menstrual complaints.

About 15 studies focus on adolescents and describe age at menarche, timing of reproductive maturation and menstrual characteristics, including normative patterns of menstrual function and frequency of dysmenorrhea ${ }^{30-48}$ (Table 3). Most of these studies sampled student populations, while a few used community-based samples.

A few studies have quantified blood loss during menstruation and estimate the prevalence of menorrhagia based on the standard definition of blood loss exceeding $80 \mathrm{~mL},{ }^{49}$ although only one used a population-based sampling strategy. ${ }^{40}$ These latter studies provide useful information on correlations among blood loss, various measures of body iron and anaemia.

Finally, a few qualitative studies have included queries about women's definitions of menstrual disorders, their experience and perception of menstrual dysfunction and their access to treatment and health services. ${ }^{12,23,50-52}$ Some others focus on providers' perceptions of menstrual dysfunction and knowledge about treatment protocols. ${ }^{53}$ These qualitative studies identify gaps between the potential demand for and the availability and quality of services in the primary health care setting.

Studies do not use consistent definitions of menstrual disorders. We summarised results in five broad categories of menstrual dysfunction: abnormal uterine 
Table 1. Summary of data on prevalence of menstrual complaints in the past three months from Family Formation Patterns and Health survey. ${ }^{4,5}$

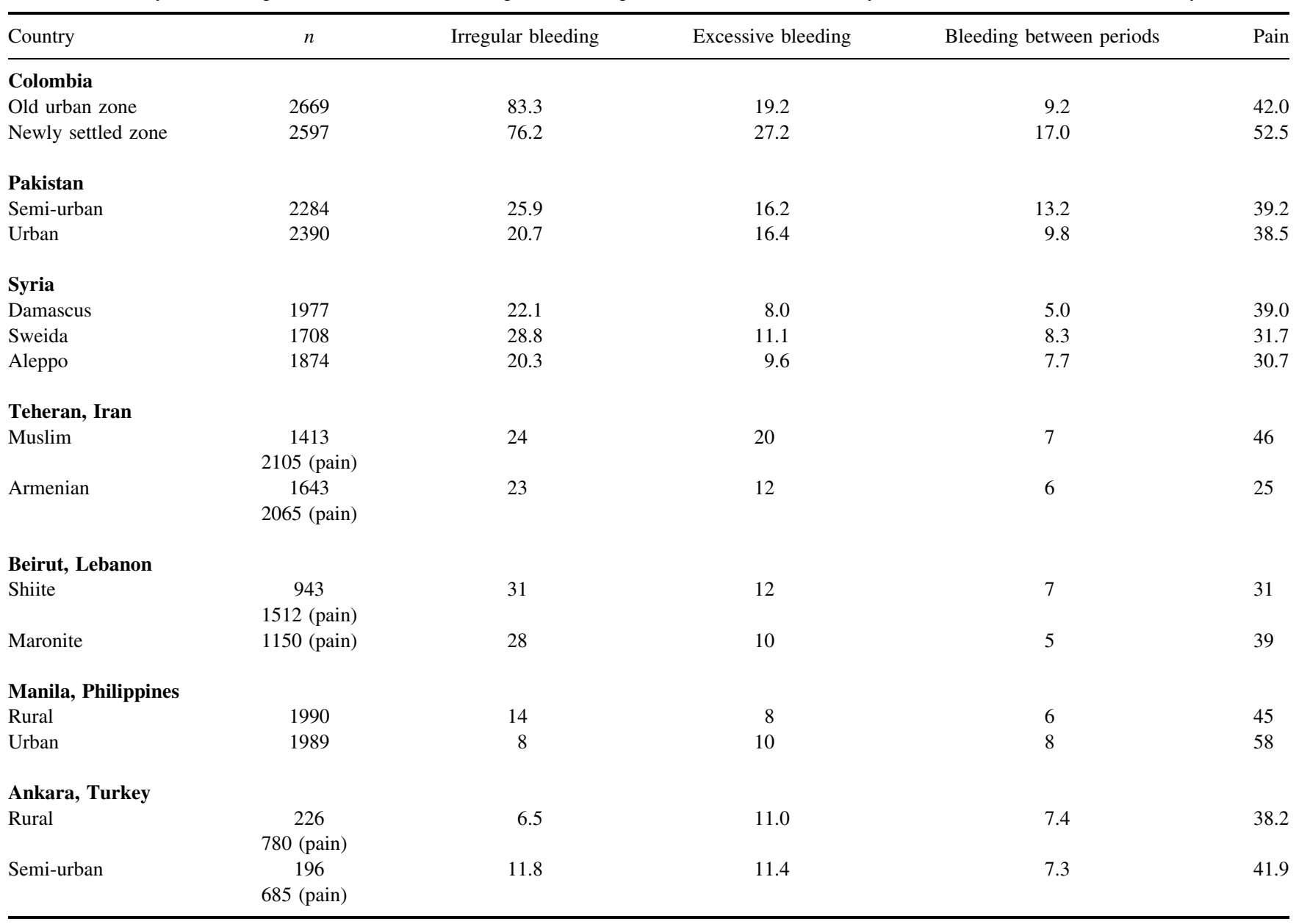

bleeding, amenorrhea/oligomenorrhea, irregular cycles, dysmenorrhea and any menstrual complaint. Abnormal uterine bleeding includes definitions consistent with menorrhagia or polymenorrhea including (1) a long duration of menstrual flow, (2) excessive, heavy or profuse bleeding, (3) frequent periods or short cycles and (4) spotting or intermenstrual bleeding. Amenorrhea/oligomenorrhea includes all definitions consistent with amenorrhea (no menses for three or more months), oligomenorrhea (menstrual cycles of 35-90 days) or infrequent menses. The term irregular menses is included in a number of surveys, thus we report it here even though it lacks a commonly accepted meaning among women or across cultures. Dysmenorrhea includes pain, backaches, abdominal pain or cramps with menstruation. Finally, a number of studies group diverse complaints, such as irregular cycles, frequent periods, spotting, heavy bleeding and menstrual pain into a single category of 'any menstrual problems'. Although this category is of little utility for determining aetiology, diagnosis or treatment, it captures the relative importance of menstrual morbidity as a health priority.

\section{Results}

Approximately $4-8 \%$ of women report having menstrual periods longer than 7-8 days when interviewed ${ }^{6,20}$ (see Table 2). Similarly, the self-reported prevalence of excessive, profuse or heavy bleeding was $4-9 \%$ in most studies, ${ }^{6,7,12,23}$ although in the WHO multicountry study, ${ }^{4,5}$ the three month, self-reported prevalence of excessive bleeding was higher, ranging from $8 \%$ to $27 \%$ (Table 1). The frequency increases when the sample is limited to older women. ${ }^{6}$ Self-reported three month prevalence of bleeding between periods was $5-17 \%$ in the WHO multicountry study, ${ }^{4,5}$ while in other studies $1-11 \%$ of women report spotting or intermenstrual bleeding. ${ }^{19,20,22,23}$ Short cycles of less than 21 days were self-reported by $1 \%$ of women in India $^{6,11}$ while $6 \%$ of women in Turkey complained of having frequent periods. $^{19,20}$

Prevalences of abnormal uterine bleeding were higher when women were interviewed by a physician with $15 \%$ of women diagnosed with menorrhagia ${ }^{7}$ and $15 \%$ reporting profuse bleeding ${ }^{11}$ to a physician in India. In the Turkish 
study, a total of $25 \%$ of women aged 15-44 complained of having either long or frequent periods and/or spotting to the physician, with $16 \%$ then clinically diagnosed with abnormal uterine bleeding. ${ }^{19,20}$ Two studies that measured actual blood loss and defined menorrhagia as blood loss exceeding $80 \mathrm{~mL}$ found a prevalence of $11 \%$ in the Philippines ${ }^{14}$ and $20 \%$ in China. ${ }^{18}$

Only a few of the adolescent studies (Table 3) provided data on menstrual flow. In Nigeria, $1 \%$ of girls reported having menses that lasted more than 7 days, $4 \%$ reported having heavy flow and $24 \%$ reported having cycles shorter than 21 days. ${ }^{39}$ In another Nigerian study, $12 \%$ of teenage girls had menorrhagia based on documented blood loss of $>80 \mathrm{~mL}^{40}$ In India, ${ }^{31}$ profuse periods were reported by $8 \%$, and in Turkey, short cycles were reported by $7 \%$ of adolescent girls. ${ }^{34}$ In the Dominican Republic, $18 \%$ reported hypermenorrhea (not defined). ${ }^{47}$

Abnormal uterine bleeding may be a symptom of other reproductive, gynecologic or systemic morbidities but few studies from developing countries have evaluated menstrual symptoms as a risk marker for other reproductive morbidities. An important study from the Gambia ${ }^{23}$ found that women with a history of infertility and pelvic tenderness were more than three times as likely to report having heavy or prolonged bleeding compared to women without these conditions. Additionally, women with cervical tumours were almost six times more likely and women with pelvic tenderness or adhesions were about three times more likely to report spotting than other women. Women with endometrial tuberculosis were twice as likely to report having menorrhagia as control women in one Indian study $(16 \% \text { vs } 8 \%)^{42}$ and menorrhagia can be a symptom of haemorrhagic dengue fever. ${ }^{54-56}$

Among women of reproductive age, the prevalence of amenorrhea ranged from approximately $5 \%$ to $13 \%{ }^{7,19,20,26-28}$ with the highest prevalence reported in a study of medical residents. ${ }^{29}$ The prevalence of oligomenorrhea or cycles longer than 35 days ranged from $8 \%$ to $22 \% .^{7,8,11,26-28}$ Reports of irregular bleeding in the past three months in the WHO multicountry study ranged from $8 \%$ to $83 \% .^{4,5}$ In other studies, the frequency of irregular cycles ranged from $5 \%$ to $16 \%$, with higher prevalences generally reported after medical interviews $(9-16 \%)$ than lay interviews $(5-15 \%) .^{6,7,11,12,21,23}$ However, the highest prevalence of irregularity was reported in a study of a selected population, Vietnamese factory workers $(30 \%){ }^{17}$ In Lebanon, $15 \%$ of women who had ever visited a gynecologist sought care for menstrual irregularity at their last gynaecological visit. ${ }^{21}$ In the adolescent studies, the frequency of amenorrhea was reported to be $4 \%$ in Chile while that of oligomenorrhea was reported to be $1.1 \%$ in Nigeria, ${ }^{39} 8 \%$ in Turkey ${ }^{34}$ and $42 \%$ in Thailand. ${ }^{33}$ In the Gambia, women with evidence of cervical tumours were about 2.5 times more likely and women with adnexal tumours were 4.5 times more likely to report irregular menstruation in the past three months than women without tumours. $^{23}$ Oligomenorrhea/amenorrhea may also be a symptom of genital tuberculosis. ${ }^{54,58}$

Between $25 \%$ and $58 \%$ of women participating in the WHO multicountry study reported having menstrual pain in the past three months. ${ }^{4,5}$ In other studies, $15-70 \%$ of adult women reported dysmenorrhea with higher frequencies reported in physician interviews. $6,7,11,12,15,16,19,22,24,28$ Severe pain or pain that kept a woman from work or her daily activities ranged from $3 \%$ to $18 \%,{ }^{6,16,23}$ with one report in Niue of $58 \%$ of women reporting 'excessive' pain. $^{22}$ Among adolescents, the prevalence of dysmenorrhea was higher with approximately $18-88 \%$ reporting some pain ${ }^{30-32,34-39,41-48}$ and $3-20 \%$ reporting severe pain or pain sufficient to cause them to miss school, work or daily activities. $30,31,34,36,39,41,42,45,46,48$ In the Gambia, women with infertility and women with pelvic tenderness were 3.5 and 5 times more likely to report disabling menstrual pain, respectively. ${ }^{23}$

As gynaecologic morbidity surveys begin to evaluate the relative frequency of menstrual complaints and related care-seeking behaviour, they permit assessment of the relative importance of menstrual disorders as a health concern. In India, menstrual disturbances were between the first and fourth most commonly reported gynaecological complaints. ${ }^{9,10}$ In the Philippines, menstrual disorders were the third most commonly reported gynaecologic morbidity. ${ }^{13}$ In Turkey, abnormal uterine bleeding was the third most commonly reported gynaecological complaint and the fourth most commonly diagnosed gynaecological morbidity among adult women, ${ }^{19,20}$ while among adolescents who consulted a gynecologist menstrual disorders and dysmenorrhea were the most common complaints. ${ }^{34}$ In Lebanon, menstrual irregularity and bleeding problems were between the second and fourth most common reasons for seeking gynaecological care. ${ }^{21}$ Perhaps most notably, in Niue, where some of the highest prevalences of menstrual disorders were reported, women, when asked to rank their health care needs, ranked menstrual problems as their third priority for health education and their fourth most important health priority. ${ }^{22}$

Surveys of women in medical care settings ${ }^{19-21}$ and studies that offered care in conjunction with survey participation $^{7,10,11,23}$ demonstrate that women do seek treatment for menstrual complaints. Furthermore, qualitative data from the Gambia ${ }^{23}$ demonstrate that women purchase paracetamol for dysmenorrhea and are aware that iron tablets are recommended for women with heavy bleeding. However, they were unaware of any Western medicines that could reduce blood flow or treat abnormal uterine bleeding. Qualitative studies in Pakistan ${ }^{50}$ and Brazil (M Luick, unpublished observations) have documented both the difficulty women experience in obtaining care for menstrual problems and the lack of knowledge among primary care providers about protocols for the diagnosis and treatment of menstrual disorders. Training of primary care professionals and access to diagnostic and 
Table 2. Summary of data on prevalence of menstrual disorders among women of reproductive age in developing countries.

\begin{tabular}{|c|c|c|c|c|c|c|}
\hline Author, year, country & Design & $\begin{array}{c}\text { Population } \\
\text { characteristics }\end{array}$ & $\begin{array}{c}\text { Amenorrhea/ } \\
\text { oligomenorrhea/irregular }\end{array}$ & $\begin{array}{l}\text { Abnormal uterine } \\
\text { bleeding }\end{array}$ & Dysmenorrhea & Menstrual problems \\
\hline $\begin{array}{l}\text { Khatri and Gupta, } \\
\text { 1978, India }\end{array}$ & $\begin{array}{l}\text { community-based } \\
\text { survey; interview } \\
n=1000\end{array}$ & $\begin{array}{l}\text { age } 20-40 \text {, married, } \\
\text { parous, not using IUD, } \\
\text { oral contraceptives, } \\
\text { sterilized; no recent } \\
\text { D\&C for menstrual } \\
\text { dysfunction }\end{array}$ & irregular: $5 \%$ & $\begin{array}{l}\text { bleed }>7 \text { days: } 4 \% \text {; } \\
\text { excessive bleeding: } 9 \% \text {; } \\
\text { excessive bleeding age } \\
36-40: 28 \% \text {; cycle } \\
<21 \text { days: } 1 \%\end{array}$ & $\begin{array}{l}\text { dysmenorrhea: } 29 \% \\
\text { severe dysmenorrhea: } \\
3 \%\end{array}$ & \\
\hline Bang et al., 1989, India ${ }^{7}$ & $\begin{array}{l}\text { community-based } \\
\text { survey; cross sectional; } \\
\text { interview and clinical } \\
\text { exam } n=650\end{array}$ & age $13+$ & $\begin{array}{l}\text { amenorrhea: } 20 \% \\
\text { interview, } 5 \% \text { exam; } \\
\text { oligomenorrhea: } 22 \% \\
\text { exam; irregular: } 7 \% \\
\text { interview, } 13 \% \text { exam }\end{array}$ & $\begin{array}{l}\text { profuse periods: } 5 \% \\
\text { interview; menorrhagia: } \\
15 \% \text { exam }\end{array}$ & $\begin{array}{l}\text { dysmenorrhea: interview } \\
15 \% \text {, exam } 58 \%\end{array}$ & \\
\hline $\begin{array}{l}\text { Jeyaseelan and } \\
\quad \text { Rao, 1995, India }\end{array}$ & $\begin{array}{l}\text { prospective community } \\
\text { survey } n=2566 \text { women } \\
\text { followed for three to five } \\
\text { cycles }\end{array}$ & reproductive age & cycles $>37$ days: $12 \%$ & & & \\
\hline $\begin{array}{l}\text { Kumar et al., 1994, } \\
\text { India }^{9}\end{array}$ & $\begin{array}{l}\text { community-based survey; } \\
\text { cross sectional interview } \\
n=600\end{array}$ & age $15-44$ married & & & & $\begin{array}{l}\text { menstrual disturbances } \\
\text { in past month: } 23 \%\end{array}$ \\
\hline $\begin{array}{l}\text { Bhatia and Cleland, 1995, } \\
\text { India }^{10}\end{array}$ & $\begin{array}{l}\text { community-based survey; } \\
\text { cross sectional interview } \\
n=3600\end{array}$ & $\begin{array}{l}\text { age }<35 \text {, with at } \\
\text { least one child } \\
<5 \text { years }\end{array}$ & & & & $\begin{array}{l}\text { current menstrual disorders } \\
\text { (heavy or light bleeding, } \\
\text { irregular bleeding, painful } \\
\text { menstruation, or spotting } \\
\text { between periods): } 7 \% \text { in } \\
\text { total sample; } 11 \% \text { in } \\
\text { menstruating women }\end{array}$ \\
\hline $\begin{array}{l}\text { Bhatia et al., 1997, } \\
\text { India }^{11}\end{array}$ & $\begin{array}{l}\text { follow up of cross } \\
\text { sectional survey; } \\
\text { interview and clinical } \\
\text { exam } n=385\end{array}$ & $\begin{array}{l}\text { age }<35 \text { with } \\
\text { a child aged } \\
6-12 \text { months }\end{array}$ & $\begin{array}{l}\text { cycle }>5 \text { weeks: } 8 \% \\
\text { response to doctor } \\
\text { query; irregular: } 9 \% \\
\text { response to doctor } \\
\text { query }\end{array}$ & $\begin{array}{l}\text { profuse discharge: } 15 \% \\
\text { response to doctor query; } \\
\text { period }>5 \text { days: } 16 \% \\
\text { response to doctor query; } \\
\text { cycle }<3 \text { weeks: } 1 \% \\
\text { response to doctor query }\end{array}$ & $\begin{array}{l}\text { dysmenorrhea: } 55 \% \\
\text { response to doctor } \\
\text { query }\end{array}$ & $\begin{array}{l}\text { any menstrual problems } \\
\text { (heavy or light bleeding, } \\
\text { irregular bleeding, painful } \\
\text { menstruation, or spotting } \\
\text { between periods): } 62 \% \\
\text { response to doctor query; } \\
15 \% \text { in interview in the } \\
\text { last month }\end{array}$ \\
\hline $\begin{array}{l}\text { Intermediate Technology } \\
\text { Bangladesh, 1992, } \\
\text { Bangladesh }^{12}\end{array}$ & $\begin{array}{l}\text { focus groups, } n=8 \\
\text { groups, } 80 \text { women }\end{array}$ & $\begin{array}{l}\text { urban, rural and } \\
\text { periurban groups }\end{array}$ & irregular: $3 \%$ & heavy bleeding: $8 \%$ & $\begin{array}{l}\text { backaches, abdominal } \\
\text { pain, cramps and } \\
\text { lethargy: } 44 \%\end{array}$ & \\
\hline $\begin{array}{l}\text { Philippine National Safe } \\
\text { Motherhood Survey, 1993, } \\
\text { Philippines }^{13}\end{array}$ & $\begin{array}{l}\text { nationally representative } \\
\text { sample; interview } \\
n=8481\end{array}$ & $\begin{array}{l}\text { age } 15-49, \text { ever } \\
\text { pregnant }\end{array}$ & & & & $\begin{array}{l}\text { menstrual problems during } \\
\text { last menstrual period } \\
\text { (severe pain that kept you } \\
\text { from your normal activities, } \\
\text { changes in the duration of } \\
\text { your period or in the amount }\end{array}$ \\
\hline
\end{tabular}


Cheong et al., 1991,
Philippines $^{14}$

Thongkrajai et al., 1999, Thailand ${ }^{15}$

$\mathrm{Ng}$ et al., 1992

Singapore ${ }^{16}$

Matsuda et al., 1997, Vietnam $^{17}$

Gao et al., 1997, China ${ }^{18}$

Filippi et al., $1997^{19}$ and Bulut et al., 1997,

Turkey $^{20}$

Deeb et al., 2003,

Lebanon $^{21}$

Taylor et al., 1985,

Niue $^{22}$

Walraven et al., 2002,

Gambia $^{23}$ convenience, age-

stratified sample,

recovery of menstrual

pads $n=80$

cross sectional survey

$n=634$

random sample of

households; cross

sectional; questionnaire

$n=415$

cross sectional survey

of factory employees

from 10 factories

$n=150$ women

convenience sample

$n=421$

systematic sample of health center patients; interview (symptom checklist of problems in last 3 months) and clinical exam $n=696$

community-based, cross sectional survey

$$
n=779
$$

ge $15-49$, ever

married, ever

visited gynecologist

community-based census; (1) aged 15+; (2) aged

interview and clinical 15-49 pre-menopausal,

exam: (1) $n=452 ; \quad$ without hysterectomy,

(2) $n=327$

not on Depo-Provera

community-based survey; interview and clinical

exam $n=607$

menstruating, not

using hormonal

contraception

octor; $8 \%$ to

fieldworker menstrual blood

loss $>80 \mathrm{~mL}: 11 \%$ period irregular): 5-6\%

irregular: $15 \%$

complaint at last

gynecology visit

factory-based survey,

age 19-45 dysmenorrhea: $45 \%$

$1+$ episodes menstrual cramps or pain in past year: $51 \%$, work

leave in past year: $10 \%$

blood loss >80 mL: $20 \%$

long bleeding ( $>8$ days):

$8 \%$ interview, $18 \%$

response to doctor

query; frequent periods:

6\% interview, 9\%

response to doctor query;

spotting: $3 \%$ interview,

$5 \%$ response to doctor

query; abnormal uterine

bleeding: $25 \%$ response

to doctor query, $16 \%$

diagnosed by doctor

bleeding: $10 \%$ complaint

at last gynecology visit

heavy menstrual bleeding:

$6 \%$ all women, $36 \%$ women

aged 15-49; intermenstrual

bleeding: $11 \%$ women aged

15-49

heavy/prolonged bleeding:

$4 \%$ to doctor and

fieldworker; spotting:

$8 \%$ to doctor, $1 \%$

to fieldworker menstrual pain: $21 \%$

interview, $56 \%$

response to doctor

query

excessive menstrual

pain: $58 \%$ women

aged 15-49

pain that kept you

from normal activities:

$14 \%$ to doctor, $10 \%$ to

fieldworker

dysmenorrhea: $68 \%$ menstrual problems:

$25 \%$ all women

any menstrual problem: $35 \%$ to doctor, $21 \%$ to fieldworker

interview $n=53$ 


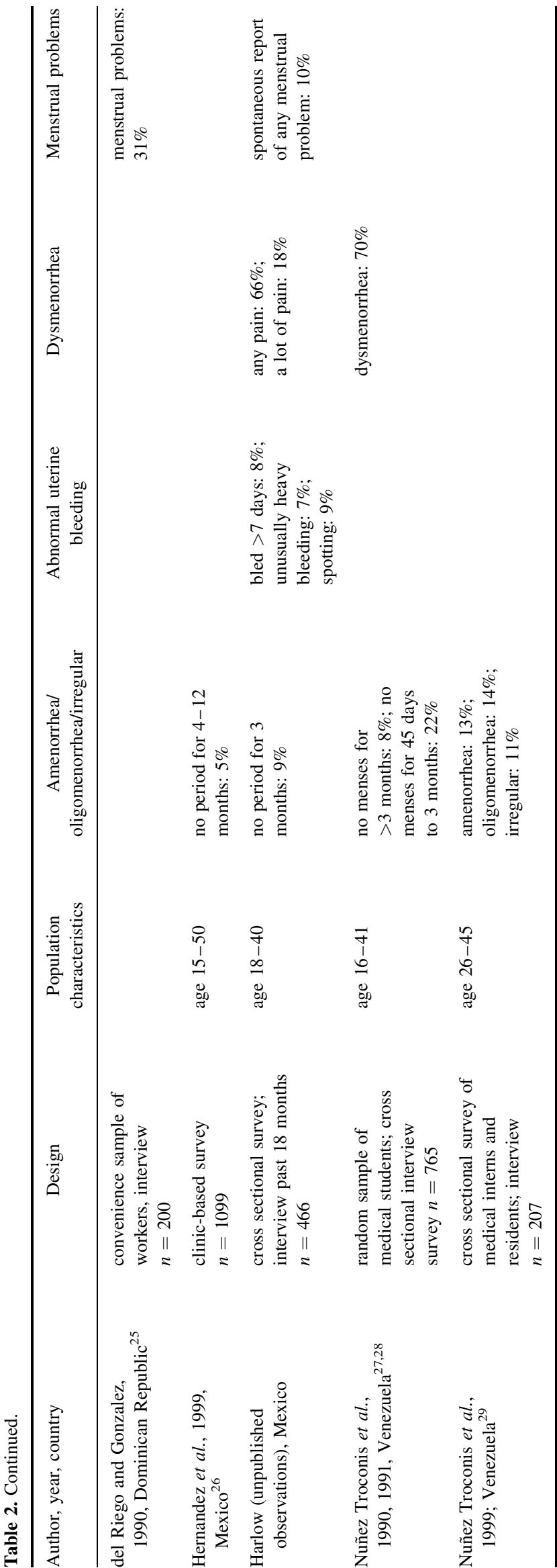

treatment protocols is also recognised to be a major barrier in India.

\section{Discussion and conclusion}

This review of the literature on the prevalence of menstrual disorders in developing countries suggests that the prevalence of menstrual morbidity is broadly comparable to that observed in developed countries. Furthermore, it suggests that menstrual morbidities constitute an important area of unmet need for reproductive health services for women in developing countries. The literature upon which this review is based is quite limited and the definition of menstrual dysfunction is often imprecise. Nonetheless, the data do support the conclusion that menstrual dysfunction represents a problem for women in developing countries as is true elsewhere.

In developing countries, abnormal uterine bleeding appears to affect about 5-15\% of women of reproductive age and probably a higher percent of women in older age groups. Data on prevalence of abnormal uterine bleeding in Europe and North America is also limited, but it is a major cause of gynaecological morbidity, affecting up to one in five women at some point during their reproductive life span. ${ }^{59}$ Nine to fourteen percent of reproductive-aged women have blood loss that exceeds $80 \mathrm{~mL}^{49}$ and abnormal uterine bleeding is a leading indication for hysterectomy, the most common non-obstetric operation in women in both the United States and the United Kingdom. ${ }^{60}$ Abnormal uterine bleeding is also reported to be the primary indication for hysterectomy in Trinidad. ${ }^{61}$

Abnormal uterine bleeding is of concern both because it may have serious medical consequences and because excessive or prolonged bleeding may cause undue disruption of women's daily activities, particularly if sanitary protection is not easily available. Prolonged and excessive bleeding may provoke or exacerbate anaemia and, in a certain percentage of cases, may eventually be life threatening if left untreated. The critical level of blood loss has traditionally been defined as $80 \mathrm{~mL} .{ }^{49}$ Although Janssen et al. argue that anaemia is not observed among women in the United Kingdom until a threshold loss of $120 \mathrm{~mL}$ is reached, ${ }^{62}$ most studies in developing countries concur with the $80 \mathrm{~mL}$ cutpoint to define the upper limit of normal blood loss, ${ }^{14,18,40}$ while Andrade et al. ${ }^{63}$ argue that iron depletion may be detectable with blood loss as low as $60 \mathrm{~mL}$ among undernourished women in Brazil. Although, iron supplementation is typically recommended, Fazio-Tirrozzo et $a l .{ }^{64}$ have recently argued that supplementation will not improve iron status if significant blood loss occurs during menstruation.

The lack of awareness about the potential importance of reducing menstrual flow when women are anemic and lack of knowledge among women and providers about treatment alternatives is of some concern. Treatment

(C) RCOG 2004 Br J Obstet Gynaecol 111, pp. 6-16 
recommendations should focus on reducing the quantity of blood loss in addition to supplementing iron. The Gambian study, demonstrating the association between menstrual symptoms and other reproductive morbidities, underscores the importance of ruling out infection and cancer when women present with abnormal uterine bleeding. More research is needed on the prevalence of abnormal uterine bleeding, particularly among older women and in regions where fibroids are common. The need for hysterectomy services and the utility of training in endometrial ablation technique should be evaluated in regions where abnormal uterine bleeding is prevalent.

The frequency of amenorrhea ranged from about $5 \%$ to $9 \%$ in the developing country studies, which is similar to the prevalence reported in population-based surveys in Europe. $^{65}$ Although infrequent cycling is not generally associated with adverse health outcomes, irregular cycles or amenorrhea may be associated with infertility, which is a major concern of women in many developing countries. ${ }^{66}$ Amenorrhea may also be problematic when it is a symptom of other health problems that require treatment, such as hypothyroidism, ${ }^{26}$ endometrial tuberculosis ${ }^{57}$ or AIDS wasting. ${ }^{67}$ Irregular bleeding may also be a sign of cancer, particularly in postmenopausal women, and the Gambian study did find an association between cervical and uterine tumours and irregular bleeding. ${ }^{23}$

As might be expected, about $25-50 \%$ of adult women and roughly three-quarters of adolescents experience some pain with menstruation, with about $5-20 \%$ of women reporting severe dysmenorrhea or pain that prevents them from participating in their usual activities. These frequencies are comparable to those found in studies of American, European and Australian women. ${ }^{68}$ Again, although not life threatening, painful menstruation can be particularly disruptive to a woman's daily life and productivity. In the absence of appropriate pain relief, women with severe dysmenorrhea may need to refrain from their normal activities. Several effective and relatively inexpensive interventions that may be appropriate for use in developing countries are currently available. First, the most effective treatment for dysmenorrhea and the first line of treatment for menorrhagia not attributable to infection are the nonsteroidal anti-inflammatory drugs (NSAIDs). Introduction of appropriate products, such as mefenamic acid, as opposed to aspirin, which might provoke bleeding problems, or acetaminophen, which is ineffective for either complaint should be promoted. Research on the efficacy of indigenous therapies should also be encouraged. Furthermore, dysmenorrhea may also be associated with other reproductive morbidities, such as infection, thus clinical evaluation of chronic or severe menstrual pain may be warranted.

Traditional cultures of silence often surround menstruation and may inhibit women from obtaining information about menstruation or from seeking care for menstrual morbidities. Cultures of silence can also be one reason for the differential reporting of menstrual complaints in field surveys as compared with clinical exams. In the Gambia, ${ }^{23}$ women customarily speak to no one except their mothers about their menstrual periods, thus in many instances only the study gynecologist was able to elicit information on menstrual complaints. In the United Kingdom, general practitioners have suggested that South Asian women may underreport menorrhagia, and ethnographic research suggests this lack of care-seeking is because these women value heavy periods, which are believed to cleanse the body. ${ }^{52,53}$ An alternative explanation often offered for the differential reporting to medical providers is women's expectation that she will receive treatment in the clinical setting.

Although the extant studies are sufficient to suggest that menstrual morbidities are prevalent and may present a similar level of burden to women in developing countries as is found in the United States and Europe, the data are scant. More country-specific information on the prevalence of individual menstrual morbidities is needed as is information on the cost-effectiveness and feasibility of simple medical interventions. Future reproductive health surveys should include more precise and reliable questions to elicit information on the frequency and health impact of menstrual disorders. ${ }^{69}$

Primary care and reproductive health programs should also evaluate their capacity for addressing menstrual complaints. Packages of reproductive health care provided in middle income developing countries, including large parts of Latin America and the Middle East and some parts of Asia, could certainly include modules for education, diagnosis and treatment of most menstrual morbidities. In addition to the appropriate use of NSAIDs and antifibrinolytic agents, choice of contraceptives should also be carefully evaluated regarding the possibility that they may ameliorate or exacerbate menstrual disorders. Hormonal contraceptives can reduce the amount and duration of bleeding as well as severity of menstrual pain. Most IUDs tend to augment blood loss and thus may be a particularly poor choice for women who already perceive their blood loss to be excessive. However, progestin-releasing IUDs effectively reduce blood loss and may be an appropriate choice for some women. Finally, to the extent that increases in amount, frequency or duration of menstrual bleeding are a complaint only because of lack of adequate sanitary protection options, a simple intervention would be to define the specific sanitary needs of a community and provide culturally appropriate products. 1,12

In summary, menstrual morbidities constitute an important unmet area of reproductive health services for women in developing countries and more attention should be given to inclusion of diagnosis and treatment of menstrual complaints within reproductive health care programs. Relatively simple and inexpensive therapies are currently available to address a range of menstrual complaints and monitoring of menstrual symptoms may be important in efforts to reduce pelvic infections and anaemia. More attention 
Table 3. Summary of data on prevalence of menstrual disorders among adolescents in developing countries.

Author, year, country Design Population

\begin{tabular}{lll}
\hline Aggarwal et al., 1997, India & household survey, & age $11-18$, rural, \\
menstruating
\end{tabular}

Vaidya et al., 1998, India ${ }^{31}$

Singh et al., 1999, India ${ }^{32}$

Piya-Anant et al., 1997, Thailand $^{33}$

Vicdan et al., 1996, Turkey ${ }^{34}$

Demir et al., 2000, Turkey ${ }^{35}$

Montero et al., 1999, Morocco ${ }^{36}$

Thomas et al., 1990, Nigeria ${ }^{37}$

Odujinrin and Ekunwe, 1991, Nigeria $^{38}$

Fakeye and Adegoke, 1994 Nigeria $^{39}$ cross sectional survey in three schools $n=574$

student survey $n=130$

cross sectional

questionnaire survey in

schools $n=3721$

cross sectional interview

in 32 schools $n=13,665$

cross sectional

questionnaire survey in

schools

convenience sample in

schools $n=391^{*}$

cross sectional

questionnaire and interview

survey of university students

$$
n=768
$$

cross sectional survey

of school girls $n=950$

cross sectional interview

survey in seven public

schools $n=361$ menstruating schoolgirls irregular: $17 \%$

age $10-17$

age $13-17$

menstruating school girls,

age $10-17$

age $13-18$

age $14-18$

menstruating girls*

age $12-18$

age $15-34$

age $10-18$

menstruating schoolgirls age $11-19$ cycles $\geq 35$ days: $4 \%$

Amenorrhea/
oligomenorrhea/irregular

irregular: $2 \%$

menses every other month:

$42 \%$; menses every

2-3 months: $10 \%$

cycles $>35$ days: $8 \%$

irregular: $27 \%$

irregular: $29 \%$

\section{irregular: $13 \%$}

cycle $\geq 37$ days: $1.1 \%$
Abnormal uterine bleeding

Dysmenorrhe

dysmenorrhea: $71 \%$; requiring analgesics: $11 \%$; affect daily

activity: $6 \%$

dysmenorrhea: $55 \%$; requiring medication: $16 \%$; miss school: $5 \%$

dysmenorrhea $41 \%$

menorrhagia: $1 \%$

cycles $<20$ days: $7 \%$

pain during menstruation: $78 \%$; frequently miss school: $26 \%$

dysmenorrhea: $39 \%$

abdominal pain during cycle: $88 \%$;

use medications: $21 \%$;

miss school: $7 \%$

dysmenorrhea: $72 \%$

dysmenorrhea: $72 \%$

duration $>7$ days: $1 \%$

heavy flow: $4 \%$; cycle

length $<21$ days: $24 \%$ pain before/during period: $85 \%$; severe pain: $17 \%$ 
Barr et al., 1998, Nigeria ${ }^{40}$

community-based survey; interview and recovery of

menstrual pads $n=307$

Schmidt and Diefenthaeler Herter, 2002, Brazil ${ }^{4}$

Barros et al., 1987, Brazil ${ }^{42}$

González Bahamonde and Ibarra Farias, 1999, Chile

Parra et al., 1995, Chile ${ }^{44}$

Rojas Martinez et al., 1997, Colombia $^{45}$

Onatra and Posso, 1994,

Colombia $^{46}$

Barranco Ventura et al., 1993 Dominican Republic ${ }^{47}$

Pedro-Nuevo et al., 1998 Mexico $^{48}$ cross sectional survey in

one school $n=92$

cross sectional interview survey; university students $n=1006$

cross sectional interview survey; university students $n=242$

cross sectional interview survey; secondary school students $n=2269$

cross sectional interview

survey at one school $n=600$

cross sectional survey of

students, stratified by

socioeconomic status;

interview $n=796$

cross sectional survey of

university students $n=430$

cross sectional student survey, interview, visual analog pain

scale $n=1066$ age $<20$, non-pregnant,

nulliparous, menstruating

age $12-19$, menstruating

irregular (early or late by

more than 7 days): $28 \%$

university students

university students

age $11-20$

age $12-23$

age $9-20$

university students

age $12-24$, single amenorrhea: $4.4 \%$; irregular: $20.0 \%$

hypomenorrhea: $11 \%$ blood loss of $>80 \mathrm{~mL}: 12 \%$

pain during menstruation: $70 \%$; severe pain: $16 \%$; affect daily activities: $8 \%$

dysmenorrhea: $76 \%$; severe: $8 \%$; often missed activities: $10 \%$

dysmenorrhea: $85.2 \%$ dysmenorrhea: $27 \%$; primary dysmenorrhea: $24 \%$; severe dysmenorrhea: $4 \%$

pain with menstruation: $37-62 \%$; severe pain: $3-7 \%$

dysmenorrhea: $18 \%$ 
should specifically be given to improving the training of primary care and reproductive health professionals about the diagnosis and treatment of menstrual morbidities. As part of this effort, diagnosis and treatment guidelines should be developed that are appropriate for use in developing countries. Increased research into the prevalence of and risk factors for menstrual morbidity is also warranted.

\section{Siobán D. Harlow ${ }^{\mathrm{a}}$, Oona M.R. Campbell ${ }^{\mathrm{b}}$ \\ ${ }^{\mathrm{a}}$ Department of Epidemiology, University of Michigan, Ann Arbor, Michigan, USA \\ ${ }^{\mathrm{b}}$ Department of Infectious and Tropical Diseases, London School of Hygiene and Tropical Medicine, UK}

\section{References}

1. Harlow SD, Campbell OMR. Menstrual dysfunction: are we missing an opportunity for improving reproductive health in developing countries? Reprod Health Matters 2000;8:142-147.

2. AbouZahr C, Vaughn JP. Assessing the burden of sexual and reproductive ill-health: questions regarding the use of disability adjusted life years. Bull WHO 2000;78:655-666.

3. In: Murray CJL, Lopez AD, editors. Health Dimensions of Sex and Reproduction. Boston: Harvard University Press, 1998.

4. Omran AR, Standley CC. Family Formation Patterns and Health: An International Collaborative Study in India, Iran, Lebanon, Philippines and Turkey. Geneva: World Health Organization, 1976:335-372.

5. Omran AR, Standley CC. Family Formation Patterns and Health, Further Studies: An International Collaborative Study in Columbia, Egypt, Pakistan, and the Syrian Arab Republic. Geneva: World Health Organization, 1981:271-302.

6. Khatri R, Gupta AN. Effect of childbirth on menstrual pattern. Indian J Med Res 1978;67:66-72.

7. Bang RA, Bang AT, Baitule M, Choudhary Y, Sarmukaddam S, Tale O. High prevalence of gynaecological diseases in rural Indian women. Lancet 1989;1:85-88.

8. Jeyaseelan L, Rao PS. Effect of occupation on menstrual cycle length: causal model. Hum Biol 1995;67:283-290.

9. Kumar R, Singh M, Kaur A, Kaur M. Reproductive health behavior of rural women. J Indian Med Assoc 1994;93:128-131.

10. Bhatia JC, Cleland J. Reported symptoms of gynecological morbidity and their treatment in south India. Stud Fam Plann 1995;26:203-216.

11. Bhatia JC, Cleland J, Bhagavan L, Rao NSN. Levels and determinants of gynecological morbidity in a district in south India. Stud Fam Plann 1997;28:95-103.

12. Intermediate Technology Bangladesh. Investigation into the Sanitary Protection Needs of Poor Women in Bangladesh. Dhaka: Intermediate Technology Bangladesh, 1992.

13. National Statistics Office (NSO) Philippines and Macro International Inc (MI). National Safe Motherhood Survey 1993. Calverton, Maryland: NSO and MI, 1994.

14. Cheong RL, Kuizon MD, Tajaon RT. Menstrual blood loss and iron nutrition in Filipino women. Southeast Asian J Trop Med Public Health 1991;22:595-604.

15. Thongkrajai P, Pengsaa P, Lulitanond V. An epidemiological survey of female reproductive health status: gynecological complaints and sexually transmitted diseases. Southeast Asia J Trop Med Public Health 1999;30:287-295.

16. Ng TP, Tan NCK, Wansaicheong GKL. A prevalence study of dysmenorrhea in female residents aged 15-54 years in Clementi Town, Singapore. Ann Acad Med Singap 1992;21:323-327.
17. Matsuda S, Luong NA, Hoai NV, et al. A study of complaints of fatigue by workers employed in Vietnamese factories with newly imported technologies. Ind Health 1997;35:16-28.

18. Gao J, Zeng S, Sun BL, Fan HM, Han LH. Menstrual blood loss and hematologic indices in health Chinese women. J Reprod Med 1987; 32:822-826.

19. Filippi V, Marshall T, Bulut A, Graham W, Yolsal N. Asking questions about women's reproductive health: validity and reliability of survey findings from Istanbul. Trop Med Int Health 1997;2:47-56.

20. Bulut A, Filippi V, Marshall T, Nalbnant H, Yolasal N, Graham W. Contraceptive choice and reproductive morbidity in Istanbul. Stud Fam Plann 1997;28:35-43.

21. Deeb M, Ghorayeb F, Kabakian-Khasholian T, Yeretzian J, Aswad N. Measuring gynecological morbidity: evaluating two different data sources from Beirut. Healthc Women Int 2003;24:254-265.

22. Taylor R. Niue Women's Health Survey 1983. Technical Paper No 187. New Caledonia: South Pacific Commission, 1985.

23. Walraven G, Ekpo G, Coleman C, Scherf C, Morison L, Harlow SD. Menstrual disorders in rural Gambia. Stud Fam Plann 2002;33:261-268.

24. Céspedes Maturana L, Cornejo Araya P. Prevalencia de sintomas premenstruales y dismenorrea en mujeres de edad fertile y su relación con el ausentismo laboral. Pontif Univ Catól Chile 1997:82.

25. del Riego A, Gonzalez V. Trastornos Reproductivos en Trabajadoras de Zona Franca Industrial, San Pedro de Macorís, República Dominicana, 1989. P R Health Sci J 1990;9:127-130.

26. Hernandez I, Cervera-Aguilar R, Verdara MD, Ayala AR. Prevalence and etiology of secondary amenorrhea in a selected Mexican population. Ginecol Obstet Mex 1999;67:374-376.

27. Nuñez Troconis J, Amesty N, Sandoval J. Trastornos menstruales en estudiantes universitarias. Amenorrea y Oligomenorrea. Rev Obstet Ginecol Venez 1990;50:138-141.

28. Nuñez Troconis J, Amesty N, Sandoval J. Trastornos menstruales en estudiantes universitarias. II Menarquia y dismenorrea. Rev Obstet Ginecol Venez 1991;51:105-108.

29. Nuñez Troconis J, Girón Páez H, Nuñez Virla L. Alteraciones del ciclo menstrual en internas y residentes. Rev Obstet Ginecol Venez 1999; 59:257-262.

30. Aggarwal K, Kannan AT, Puri A, Sharma S. Dysmenorrhea in adolescent girls in a rural area of Delhi: a community-based survey. Indian $J$ Pub Health 1997;41:84-85.

31. Vaidya RA, Shringi MS, Bhatt MA, et al. Menstrual pattern and growth of school girls in Mumbai. J Fam Welf 1998;44:66-72.

32. Singh MM, Devi R, Gupta SS. Awareness and health seeking behaviour of rural adolescent school girls on menstrual and reproductive health problems. Indian J Med Sci 1999;53:439-443.

33. Piya-Anant M, Bharscharirl M, Suvanichchati S, Jirochkul V, Worapitaksanond S. Sexual maturation in Thai girls. J Med Assoc Thail 1997; 80:557-564.

34. Vicdan K, Kukner S, Dabakoglu T, Ergin T, Keles G, Gokmen O. Demographic and epidemiologic features of female adolescents in Turkey. J Adolesc Health 1996;8:54-58.

35. Demir SC, Kadayyfcy TO, Vardar MA, Atay T. Dysfunctional uterine bleeding and other menstrual problems of secondary school students in Adana, Turkey. J Pediatr Adolesc Gynecol 2000;13: $171-175$.

36. Montero P, Bernis C, Loukid M, Hilali K, Baali A. Characteristics of menstrual cycles in Moroccan girls, prevalence of dysfunction and associated behaviors. Ann Hum Biol 1999;26:243-249.

37. Thomas KD, Okonofua FE, Chiboka O. A study of the menstrual patterns of adolescents in Ile-Ife, Nigeria. Int J Gynecol Obstet 1990; 33:1-4.

38. Odujinrin OMT, Ekunwe EO. Epidemiologic survey of menstrual patterns amongst adolescents in Nigeria. West Afr J Med 1991;10: $244-249$.

39. Fakeye O, Adegoke A. The characteristics of the menstrual cycle in Nigerian schoolgirls and the implications for school health programmes. Afr J Med Med Sci 1994;23:13-17. 
40. Barr F, Brabin L, Agbaje S, Buseri F, Ikimalo J, Briggs N. Reducing iron deficiency anaemia due to heavy menstrual blood loss in Nigerian adolescents. Public Health Nutr 1998;1:249-257.

41. Schmidt E, Diefenthaeler Herter L. Dismenorréia em adolescents escolares. Adolesc Latinoam 2002;3(1):1-12.

42. Barros A, Simoes Dornellas C, Takemoto AK, Coronado MRG, Marques JA, Nishimura A. Caracterizacao epidemiológica da dismenorréia. Rev IATROS 1987;6:13-19.

43. González Bahamonde M, Ibarra Farias M. Conocimientos y practices de autocuidado sobre syndrome premenstrual y dismenorrea de un grupo de alumnas de la Facultad de Educación de la Pontificia Universidad Católica de Chile. Santiago de Chile: Pontificia Universidad Católica de Chile, 1999:83.

44. Parra I, Arrighi B, Varquez T. Análisis de la prevalencia de trastornos menstruales en una población adolescente. Rev Soc Obstet Ginecol B Aires 1995;74:223-241.

45. Rojas Martinez JC, Robles Roa CP, Rojas Martinez NA. Dismenorrea en la adolescencia. Rev Colomb Obstet Ginecol 1997;48:95-105.

46. Onatra W, Posso HJ. Comportamiento de la dismenorrea en tres grupos de adolescents de diferente clase social. Rev Colomb Obstet Ginecol 1994;45:249-254.

47. Barranco Ventura J, Peguero J, Antigua Y. Trastornos del ciclo menstrual y su relación con ciertos indicadores antro pomâtricos del estado nutricio. Rev Med Dom 1993;54:77-80.

48. Pedron-Nuevo N, Gonzalez-Unzaga LN, De Celis-Carrillo R, ReynosoIsla M, de la Torre Romeral L. Incidence of dysmenorrhea and associated symptoms in women aged 12-24 years. Ginecol Obstet Mex 1998;66:492-494.

49. Hallberg L, Hogdahl AM, Nilsson L, Rybo G. Menstrual blood loss a population study. Variation at different ages and attempts to define normality. Acta Obstet Gynecol Scand 1966;45:320-351.

50. Fikree FF, Bhatti LI, Khan A. Perceptions of Gynecological Morbidity in Women from Low Socioeconomic Settlements of Karachi, Pakistan: Final Report. Karachi, Pakistan: Aga Khan University, 1998.

51. McMaster J, Cormie K, Pitts M. Menstrual and premenstrual experiences of women in a developing country. Healthc Women Int 1997; 18:533-541.

52. Chapple A. Iron deficiency anaemia in women of South Asian descent: a qualitative study. Ethn Health 1998;3:199-212.

53. Chapple A, Ling M, May C. General practitioners' perceptions of the illness behaviour and health needs of South Asian women with menorrhagia. Ethn Health 1998;3:81-93.

54. Tripathy SN, Tripathy SN. Endometrial tuberculosis. J Indian Med Assoc 1987;85:136-140.
55. McGready R, Paw E, Nosten F. Menorrhagia caused by dengue fever Aust N Z Obstet Gynaecol 2000;40:354-355.

56. Kourí G, Guzmán MG, Bravo J. Dengue hemorragico en Cuba. Cronica de una epidemia. Bol Sanit Panam 1986;100:322-329.

57. González Coriñas M, Vidal González D, Cepero Cordero J, Lashley Oliveras ML. Dengue hemorragico. Studio clínico de 200 pacientes. Rev Cubana Med 1999;38:13-18.

58. Samal S, Gupta U, Agarwal P. Menstrual disorders in genital tuberculosis. J Indian Med Assoc 2000;98:126-127, 129.

59. Coulter A, Noone A, Goldacre M. General practitioners' referrals to specialist out patient clinics. BMJ 1989;299:304-308.

60. Bernstein SJ, McGlynn EA, Siu AL. The appropriateness of hysterectomy. A comparison of care in seven health plans. Health Maintenance Organization Quality of Care Consortium. JAMA 1993;269: 2398-2402.

61. Santha Ram NV, Murthy NVA. Abdominal hysterectomies at area hospital, Point Fortin, Trinidad, West Indies. Int J Gynecol Obstet 1989;28:137-141.

62. Janssen CA, Scholten PC, Heintz AP. Reconsidering menorrhagia in gynecological practice. Is a 30 -year-old definition still valid? Eur $J$ Obstet Gynecol Reprod Biol 1998;78:69-72.

63. Andrade ATL, Souza JP, Shaw ST, Belsey EM, Rowe PJ. Menstrual blood loss and body iron stores in Brazilian women. Contraception 1991;43:241-249.

64. Fazio-Tirrozzo G, Brabin L, Brabin B, Agbaje O, Harper G, Broadhead R. A community based study of vitamin A and vitamin $E$ status of adolescent girls living in the Shire Valley, Southern Malawi. Eur J Clin Nutr 1998;52:637-642.

65. Pettersson F, Fries H, Nillus SJ. Epidemiology of secondary amenorrhea: I. Incidence and prevalence rates. Am J Obstet Gynecol 1973; 117:80-86.

66. Inhorn MC. Infertility and the quest for conception in Egypt. In: Barlow R, Brown JW, editors. Reproductive Health and Infectious Disease in the Middle East. Aldershot, England: Ashgate Publishing, 1998: $114-132$.

67. Harlow SD, Schuman P, Cohen M, et al. The effect of HIV infection on menstrual dysfunction. $J$ AIDS 2000;24:68-75.

68. Harlow SD, Ephross SA. Epidemiology of menstruation and its relevance to women's health. Epidemiol Rev 1995;17:265-286.

69. Cleland J, Harlow SD. The value of the imperfect: the contribution of interview surveys to the study of gynaecological ill-health. In: Jejeebhoy S, Koenig M, Elias C, editors. New Approaches to the Study of Reproductive Tract Infections and Other Gynaecological Disorders: Cambridge University Press, 2003:283-321. 